\title{
Выбор технологии для корпусирования радиационно-стойкой мемристорной памяти
}

\author{
В. Жалнин, к. т. н., ${ }^{1}$ А. Трифонов², Т. Цивинская ${ }^{3}$
}

УДК 004.076.4:621.382:621.3.049.776:666.651 | ВАК 05.27.01

\begin{abstract}
Сегодня многие традиционные технологии микроэлектроники подходят к пределу своих возможностей, что вызывает растущий спрос на новые подходы к функциональной и конструктивной интеграции, активизирует поисковые работы по созданию принципиально новых микроэлектронных устройств. Одним из видов таких устройств являются мемристоры элементы энергонезависимой памяти, которые, как ожидается, в будущем могут заменить полупроводники в качестве основы если не всех, то многих функциональных классов запоминающих устройств. В МГТУ им. Н. Э. Баумана было проведено исследование, направленное на поиск материалов и технологий, пригодных для создания мемристорных систем памяти для работы в особо сложных условиях эксплуатации, в том числе при воздействии радиации.
\end{abstract}

последние годы микроэлектроника переживает очередной период качественных изменений, когда результаты многолетних исследований достигли уровня, позволяющего переводить их из области теории в плоскость практического внедрения. Вниманию отраслевой науки и инженеров-разработчиков предложены и продолжают предлагаться новые материалы, нанотехнологии позволяют получать нанометровые пленки со стабильным рассчитанным составом вещества, обладающие уникальными свойствами. Достижения в этих областях и по ряду других направлений создают базу для создания микроэлектронных устройств, работа которых основывается на новых, ранее не использовавшихся в электронике физических принципах $[1,2]$.

Многие прикладные научные исследования последнего десятилетия в области создания принципиально нового поколения устройств энергонезависимой памяти посвящены разработке резистивной памяти с произвольным доступом (англ. Resistive Random Access Memory - RRAM) [3], называемой также мемристорной памятью.

Мемристор - это микроэлектронное устройство, сопротивление которого изменяется в зависимости от протекшего электрического заряда, то есть от величины

МГТУ им. Н.Э. Баумана, доцент, zhalnin@mail.ru.

ВНИИА им. Н. Л. Духова, инженер, artneon2008@уandex.ru.

ООО «Сенсорные системы МГТУ им. Н. Э. Баумана»,

главныйтехнолог, tsivinskaya_t@mail.ru. интеграла прошедшего через компонент тока, и остается неизменным после снятия напряжения. Поэтому мемристор рассматривается сегодня в первую очередь как элемент, обладающий эффектом памяти, хотя возможны и другие варианты его применения [4]. С конструктивной точки зрения мемристор представляет собой трехслойную структуру «металл - диэлектрик - металл", в которой эффект памяти реализуется в диэлектрике. К основным классам таких диэлектриков относят некоторые оксиды металлов, твердые электролиты, халькогениды, некоторые полимеры и ряд других. Все они обладают свойством изменения сопротивления в зависимости от величины, времени прохождения и полярности тока, но механизмы, за счет которых реализуются эти свойства, у них различны.

В настоящее время в экспериментах наиболее изучены образцы мемристоров на основе халькогенидов. Халькогениды - это бинарные химические соединения халькогенов (элементов шестой группы Периодической таблицы Д. И. Менделеева) с металлами. Под действием электрического тока они могут изменять свое фазовое состояние - переходить из поликристаллической фазы в аморфную и обратно, демонстрируя при этом большое различие между значениями электрического сопротивления. Механизмом фазового перехода в халькогенидах является нагрев и охлаждение, переход происходит достаточно быстро, что позволяет использовать их в качестве диэлектрика в составе трехслойной структуры мемристора. Программирование такого элемента памяти происходит путем подачи 
электрического импульса соответствующей амплитуды и длительности.

Принципиальная пригодность конструкции на основе халькогенида доказана. Однако ей присущи недостатки, свойственные системам, использующим нагрев для процесса перехода: многократный нагрев приводит к изменению физических свойств из-за разрушения внутренней структуры вещества. В этой связи наиболее перспективными выглядят системы на основе оксидов металлов, работающие за счет перемещения вакансий кислорода в нанометровом диэлектрическом слое оксидов металлов при приложении электрического поля [5, 6].

Как уже сказано, на данном этапе освоения мемристорные структуры зарекомендовали себя прежде всего как перспективная технология реализации систем запоминания и хранения данных, позволяющая повысить степень их миниатюризации (плотность упаковки), получить новый уровень быстродействия, кратно, если не на порядок, снизить энергопотребление. Это открывает мемристорным устройствам перспективу широкого применения в электронике специального назначения, например в системах управления космической техники. Однако создание практически применимых систем мемристорной памяти связано с рядом проблем, в том числе относящихся к этапам монтажа, сборки и герметизации.

Поиск оптимальных технологий и материалов для корпусных конструкций, гарантирующих необходимую защиту систем с мемристорной памятью, стал предметом исследования, проведенного специалистами НОЦ "Нанотехнологические системы и наноэлектроника" кафедры «Проектирование и технология производства ЭА» (ИУ4) МГТУ им Н. Э. Баумана". В качестве базового элемента в данной работе был выбран металлооксидный мемристор со структурой $\mathrm{Ag}-\mathrm{AL}_{2} \mathrm{O}_{3}-\mathrm{TiO}_{2}-\mathrm{Ag}$.

Эффективность мемристорных структур критическим образом зависит от стабильного качественного состава веществ и строения кристаллических решеток пленок нанометрового размера. Соответственно, главную опасность для них представляют локальные, точечные повреждения, которые могут появляться в результате воздействия на кристалл мемристорного ЗУ механических напряжений, возникающих в подложках, на которые он устанавливается, при различных воздействиях внешней среды и нагрузках при изготовлении и эксплуатации

Механизмы запоминания, на которых основывается работа мемристоров, обеспечивают в общем случае более высокую радиационную стойкость, чем традиционные системы памяти на основе кремниевых

\footnotetext{
Работа выполнена при поддержке гранта РФФИ № 19-07-00463 A.
}

кристаллов. Тем не менее конструкция и материалы корпуса мемристорной системы, предназначенной для специальных применений, должны обеспечивать добавочную защиту от ионизирующих излучений, способную довести радиационную стойкость собранного изделия до значений, удовлетворяющих требованиям этих применений.

Исходя из этих соображений, проблематика выбора технологии и материалов для корпусирования была

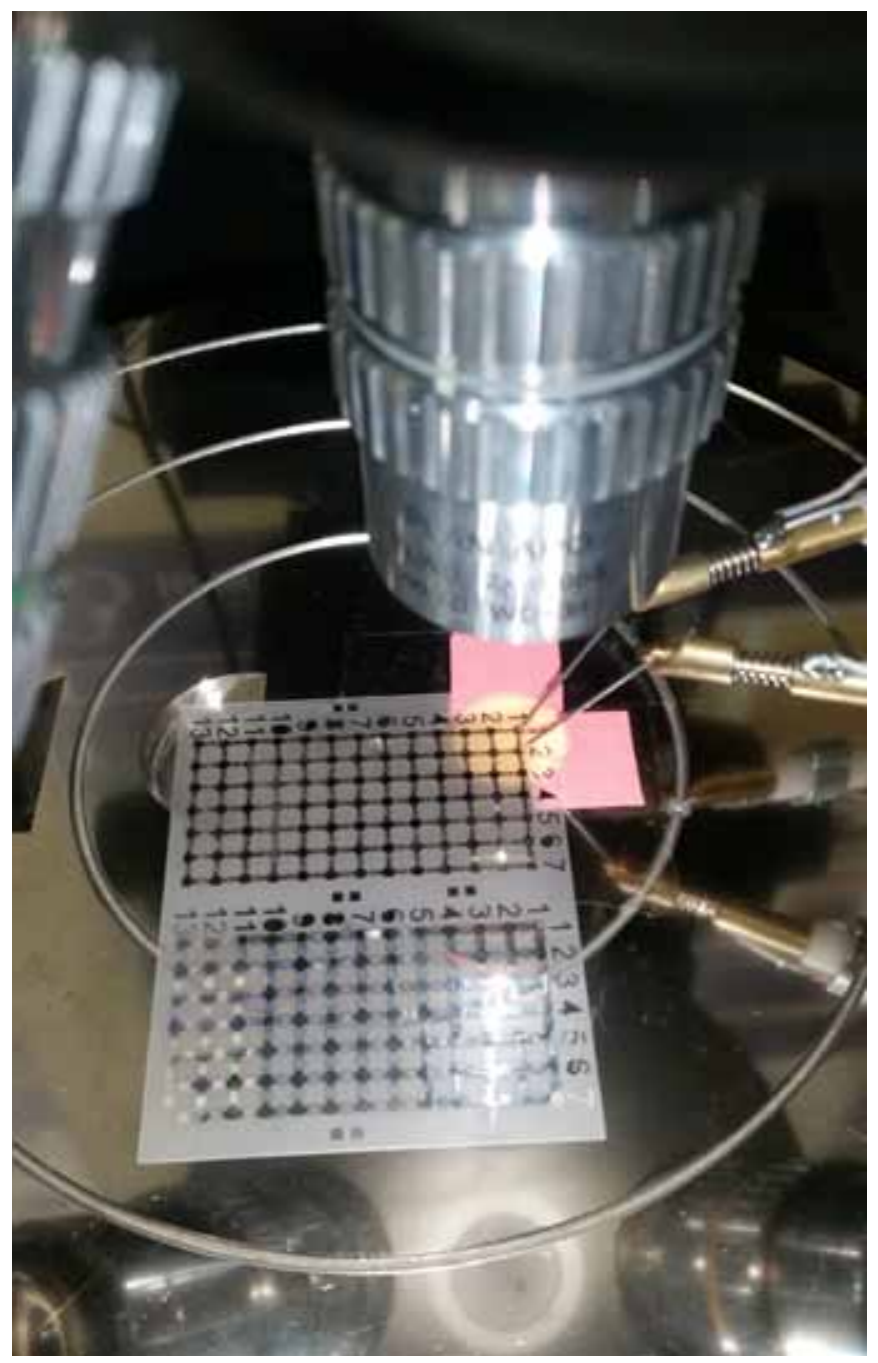

Рис. 1. Исследования свойств мемристоров, проводимые в НОЦ "Нанотехнологические системы и наноэлектроника", кафедра "Проектирование и технология производства ЭА" (ИУ4) МГТУ им Н. Э. Баумана. Экспериментальный образец представляет собой набор мемристоров на оксиде титана и оксиде алюминия между серебряными проводниками на ситаллловой подложке. Исходно все мемристоры объединены проводниками, которые по мере надобности разрезаются, позволяя изучать характеристики как отдельных мемристоров, так и их групп 


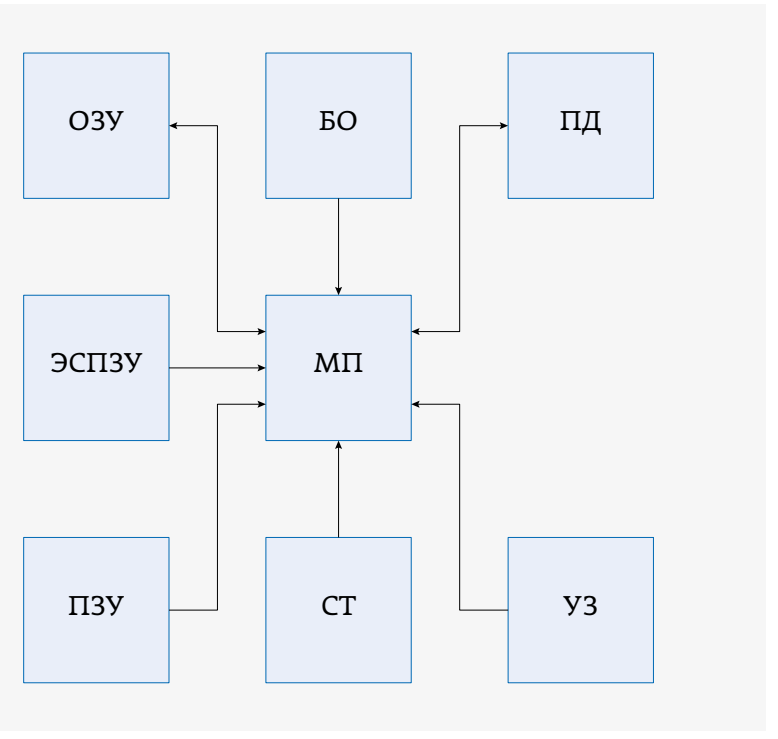

Рис. 2. Схема структурная системы запоминания данных

сосредоточена на двух аспектах: защите от механических напряжений и повреждений радиационными излучениями. В качестве модельного объекта был принят полнофункциональный модуль системы хранения данных. В его структуру (рис. 2) входят оперативное запоминающее устройство (ОЗУ), постоянное запоминающее устройство (ПзУ), электрически стираемое постоянное запоминающее устройство (ЭСПзУ), блок отладки (БО), микропроцессор (МП), память данных (ПД), блок управления загрузчиком (Уз), система тактирования (СТ).

На данном этапе исследований мемристоры принимались как элементная база ОЗУ и ЭспзУ; в дальнейшем их использование может быть рассмотрено и для других ЗУ, входящих в структуру модуля. В соответствии с современными требованиями по интеграции и миниатюризации модуль выполняется в виде микросборки с бескорпусными кристаллами, каждый из которых осуществляет функции одного из элементов схемы, приведенной на рис. 2.

В АО «Корпорация «ВНИИЭМ» с использованием обширной и многоплановой экспериментальной базы были выполнены капитальные исследования поведения различных материалов под воздействием ионизирующих излучений. По их результатам можно сделать вывод, что к материалам с высокой радиационной стойкостью относятся стекло, керамика, металлы и кремнийорганические смолы [7]. На кафедре ИУ4 МГТу им. Н. Э. Баумана также проведена работа, в ходе которой моделировалось внедрение протонов с энергией 30 МэВ в различные материалы, результаты которой подтверждают эффективность применения металлов и стекла в качестве конструкционных материалов для работы в условиях повышенной радиации

Воздействие ионизирующих излучений (гаммакванты, тепловые и быстрые нейтроны, электроны и протоны космических излучений) на электротехнические материалы сопровождается деградацией их физико-химических (прочность на разрыв, удлинение при разрыве, модуль Юнга, эластичность) и электрофизических (пробивное напряжение, электропроводность, тангенс угла диэлектрических потерь) характеристик. Повреждающий эффект определяется энергией, поглощаемой облучаемым материалом, в расчете на единицу массы, то есть поглощаемой дозой излучения.

Неорганические материалы обладают значительно более высокими по сравнению с другими веществами порогами повреждения, а деградация их свойств вызывается структурными дефектами решетки, тем более значительными, чем выше величина энергии излучения, вызвавшего смещение атомов облучаемого материала. Следовательно, корпус микросборки должен быть изготовлен из таких композитных материалов, которые способны восстанавливать стабильность своей структуры за счет перемещения отдельных атомов.

Подобными свойствами обладает стекло, однако изготовить корпус микросборки только из него невозможно хотя бы по соображениям недостаточной механической прочности и сравнительно низкой технологичности. Значит, нужно использовать композит, содержащий в своем составе примесь стеклянной массы. На сегодня таким композитом, хорошо освоенным промышленностью, является LTCC (Low Temperature Co-fired ceramic - низкотемпературная совместно спекаемая керамика) $[8,9]$.

LTCC обладает целым рядом свойств, комплекC которых делает ее уникальным материалом для создания микроэлектронных устройств:

- диэлектрическая проницаемость LTCC варьируется в пределах 6-9, тангенс угла диэлектрических потерь составляет от 0,001 до 0,006 в гигагерцевом диапазоне;

- в качестве металлизации используются металлы с низким удельным сопротивлением (Ag, Au, Pt), в отличие от высокотемпературной керамики, где используются высокоомные W и Мо;

- высокая для материалов такого типа эластичность;

- малый коэффициент теплового расширения (KTP) - 5-7 мкм / ${ }^{\circ} \mathrm{C}$, обеспечивающий механическую стабильность и сохранение линейных размеров. KTP LTCC близок к KTP основных полупроводниковых материалов, что во многих случаях позволяет монтировать полупроводниковые кристаллы непосредственно на основание платы; 


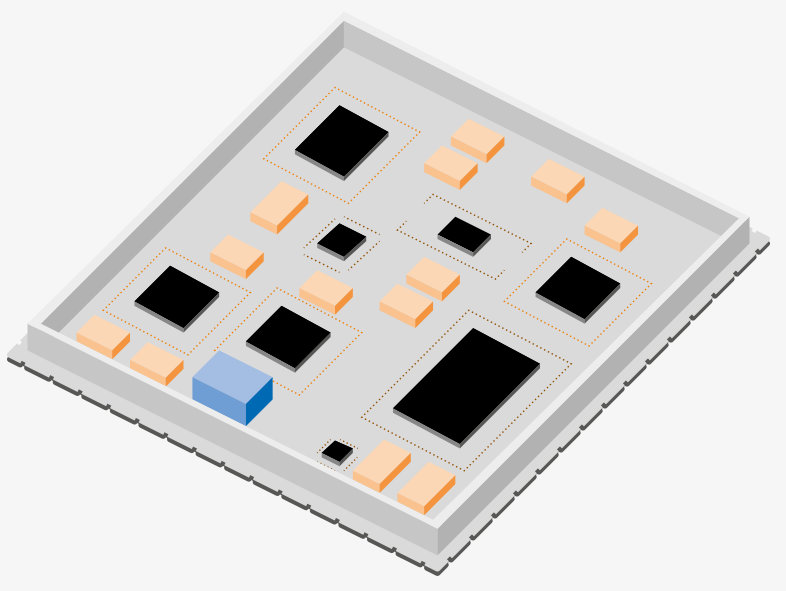

Рис. 3. 3D-модель микросборки после монтажа компонентов

- теплопроводность подложек из LTCC равняется 2-4 Вт/К, что на порядок выше, чем у печатных плат на стеклотекстолите (0,1-0,5 Вт / K);

- конструкции из LTCC герметичны и допускают возможность высокотемпературной пайки;
- материалы и процессы, составляющие технологию LTCC, оптимальны для внедрения методов 3D-интеграции, позволяют создавать корпусные конструкции нетиповых сложных форм;

- плотная структура керамики не пропускает влагу, компоненты в корпусах из LTCC могут использоваться в атмосфере с высокой влажностью.

Возможность создания многослойных, в 20 и более слоев, конструкций из LTCC обеспечивает микросборке минимальные габариты при заданном функционале. Кроме того, можно максимально сократить количество электропроводящих дорожек электрической схемы на поверхности подложки. Этим, с одной стороны, снижается риск повреждений проводящей структуры микросборки, поскольку дорожки на внутренних слоях надежно защищены; с другой стороны, исключается возникновение значительных поверхностных токов.

На верхней плоскости подложки выполняются бортики высотой 2 мм (рис. 3). Отбортовка служит для образования пространства, в которое заливается слой геля-компаунда СИЭЛ 159-356Б. Этот силиконовый компаунд, полимеризуемый по механизму полиприсоединения, показал хорошую радиационную стойкость, и заливка существенно увеличивает защиту элементов микросборки от ионизирующих излучений.

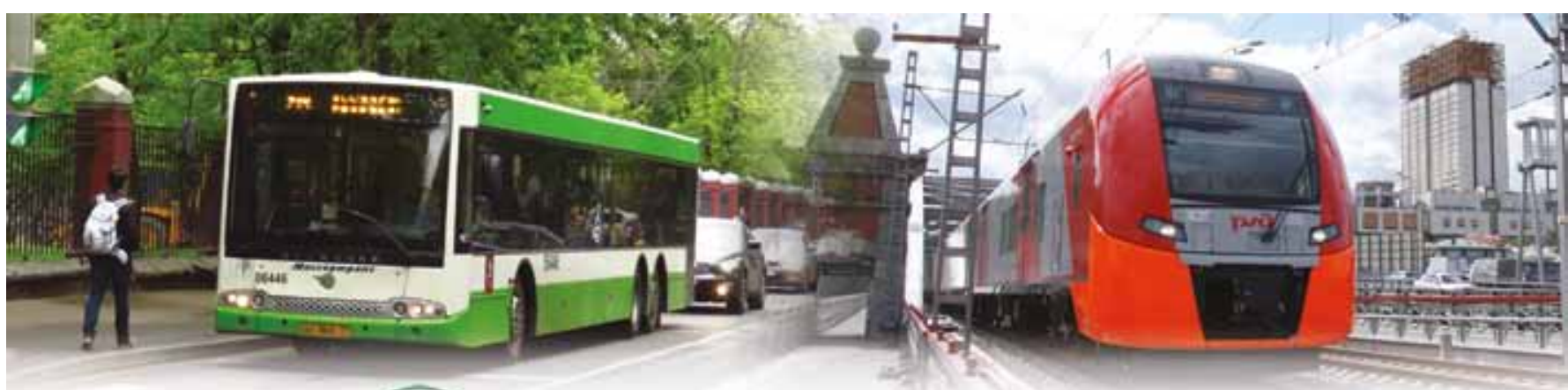

\section{Электроника $\rightleftharpoons$ Транспорт 2020}

14-я специализированная выставка электроники и информационных технопогий для поссажирского транспорта и транспортной инфраструктуры

Проводится в рамках Российской недели общественного транспорта www.publictransportweek.ru

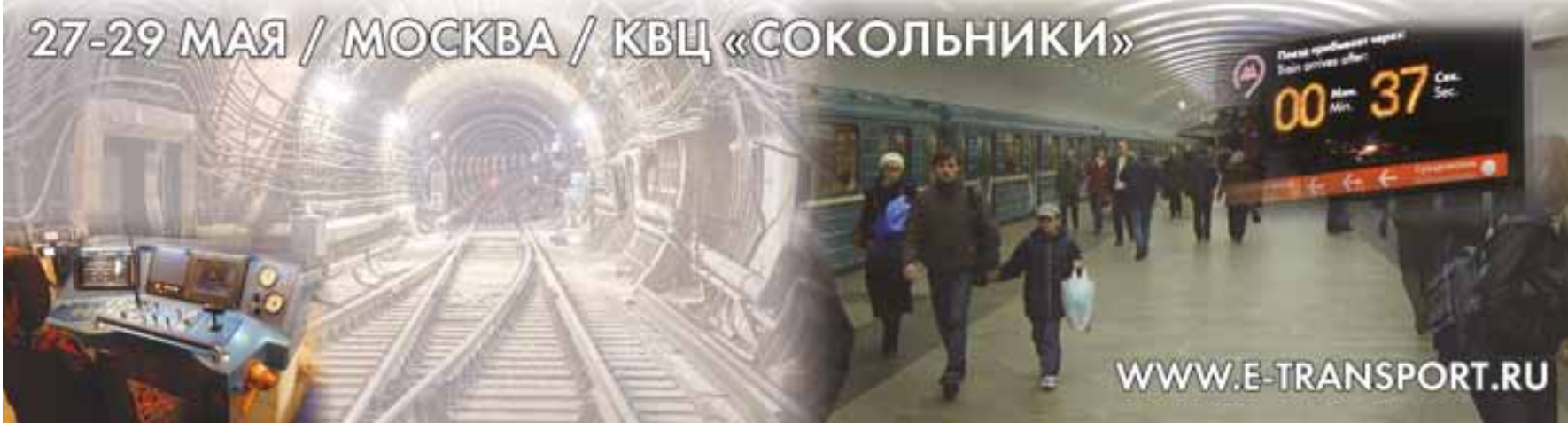


Кроме того, она улучшает герметизацию сборки; при этом после полимеризации компаунд остается в гелеобразном состоянии, так что обрыва проводников, разваренных на контактные площадки кристаллов, не наблюдается.

Масса многослойной керамической подложки многократно превышает массу кремниевого кристалла мемристора, поэтому в кристалле неизбежно возникнут локальные деформации, вызванные механическими напряжениями в керамике. Монокристаллическому кремнию свойственна высокая чувствительность к деформациям, проявляющаяся в виде заметного тензоэффекта. С целью нейтрализации данного явления кристалл мемристора соединяется с керамической подложкой через демпфер напряжений в виде прокладки толщиной 1 мм из стекла марки «Пирекс», с которой кристалл соединяется методом электростатической сварки.

Сверху сборка закрывается крышкой из нержавеющей стали и герметично соединяется с корпусом при помощи лазерной сварки. Слой нержавеющей стали служит дополнительной защитой от радиации.

Следует отметить, что оптимальное решение задачи обеспечения необходимого уровня стойкости конструкции к радиационному воздействию состоит не только в правильном подборе необходимых материалов, но и в тщательном изучении возможного влияния технологических факторов: методов и режимов производства, форм поставки исходных материалов (в виде блока, ленты, пленки, листа и т.д.), характера приложения нагрузок, контактов с другими материалами и пр.

Для улучшения качества органических материалов и материалов порошковой металлургии, стекла, керамики необходимо производить самую тщательную очистку компонентов смесей от посторонних примесей; порошковые смеси должны соответствовать единому классу помола. Сегодня в серийных LTCC-производствах используются почти исключительно готовые системы материалов зарубежного производства; если будет признана необходимость развития отечественных мемристорных технологий, возможно, придется

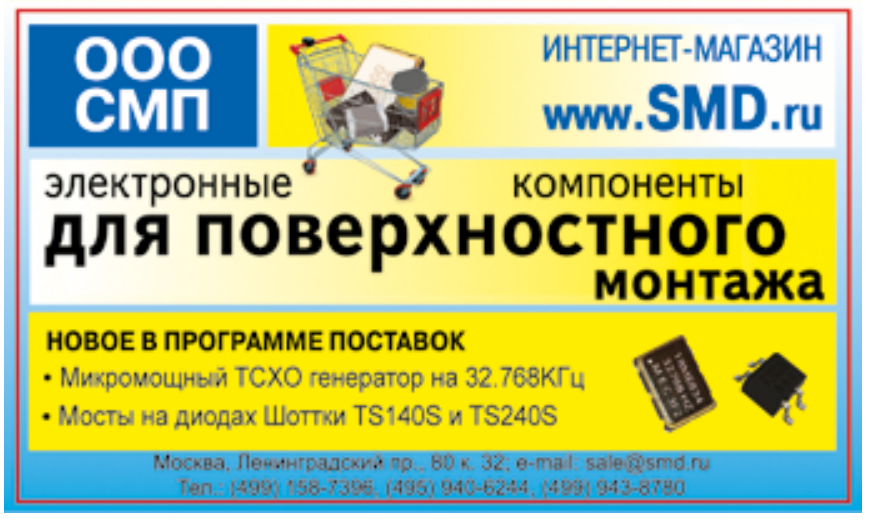

создавать для них собственные, российские системы LTCC-материалов.

Воздух и влага являются вредными примесями, оказывающими существенное влияние на радиационную стойкость материала, поэтому при подготовке сырья целесообразно использовать температурно-вакуумную обработку.

\section{ЗАКЛЮЧЕНИЕ}

Проведен анализ факторов, определяющих механическую прочность и радиационную стойкость мемристорных структур. Показана целесообразность выбора технологии низкотемпературной совместно спекаемой керамики (LTCC) для создания микросборки полнофункционального модуля системы хранения данных. Описаны конструкция такой микросборки и, частично, применяемые материалы. Обращено внимание на некоторые особенности технологических процессов, влияющие на радиационную стойкость.

\section{ЛИТЕРАТУРА:}

1. Белов А. Н., Перевалов А. А., Шевяков В.И. Мемристорные структуры для микро- и наноэлектроники. Физика и технология. Обзор // Известия вузов. Электроника. 2017. Т. 22. № 4. С. 305-321.

2. Memristor and Memristive Neural Networks / A. James (Ed.). - Rijeka: IntechOpen, 2018. 162 p.

3. Храповицкая Ю. В., Маслова Н.Е., Занавескин М.л. Перспективные структуры с эффектом памяти, созданные на основе неорганических материалов // Наука и образование. 2013. № 12. С. 329-357.

4. Шахнов В.А., Власов А. И., Поляков Ю. А., Кузнецов А.С. Нейрокомпьютеры: архитектура и схемотехника. - М.: Машиностроение, 2000. Сер. 9. 64 С.

5. Власов А. И., Жалнин В. П., Шахнов В. А. Методы повышения стабильности работы и долговечности неорганических мемристорных структур // Сб. тезисов IX Ежегодной конференции Нанотехнологического общества России / Под ред. Андреюк Д. С. - М.: НОР, 2018. С. 13-15.

6. Vlasov A. I., Zhalnin V.P., Shakhnov V.A. Methods for improvement of the consistency and durability of the inorganic memristor structures // International Journal of Nanotechnology. 16(1-3), pp. 187-195.

7. Безродных И. П., Тютнев А. П., Семёнов В.Т. Воздействие космической радиации на электротехнические материалы. Часть 2. - М.: ОАО "Корпорация "ВНИИЭМ», 2014. C. 43-56.

8. Потапов Ю. Особенности технологии проектирования и производства LTCC (технология низкотемпературной керамики) модулей // Технологии в электронной промышленности. 2008. № 3 (23). С. 59-64.

9. Перцель Я. М. Способ формирования топологии LTCC плат. Патент РФ № 2593267. 


\section{1 ИнЖИнИРИнговыЙ ЦЕНТР МИЭТ}

Инжиниринговый центр МИЭТ предлагает широкий спектр услуг в рамках выполнения НИР и ОКР в области создания радиотехнических устройств и систем в частотном диапазоне до 40 ГГц от выполнения отдельных операций до комплексных решений.

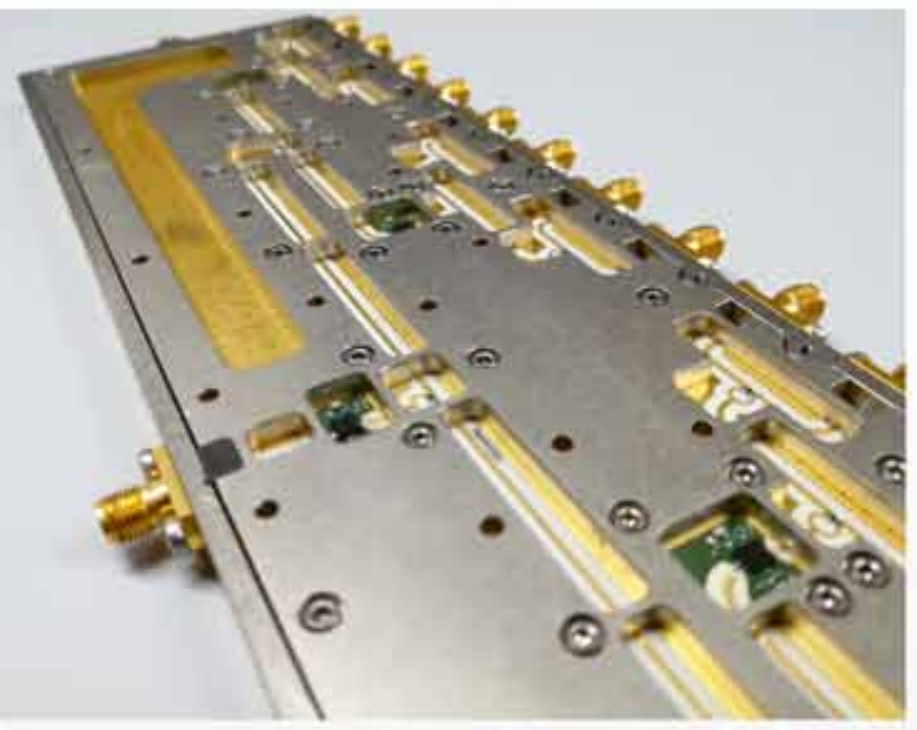

Разработка в рамках НИР или ОКР

Поставка

Аудит технических решений в области радиотехнических систем

\section{Реверс-инжиниринг}

Настройка и регулировка радиотехнических изделий

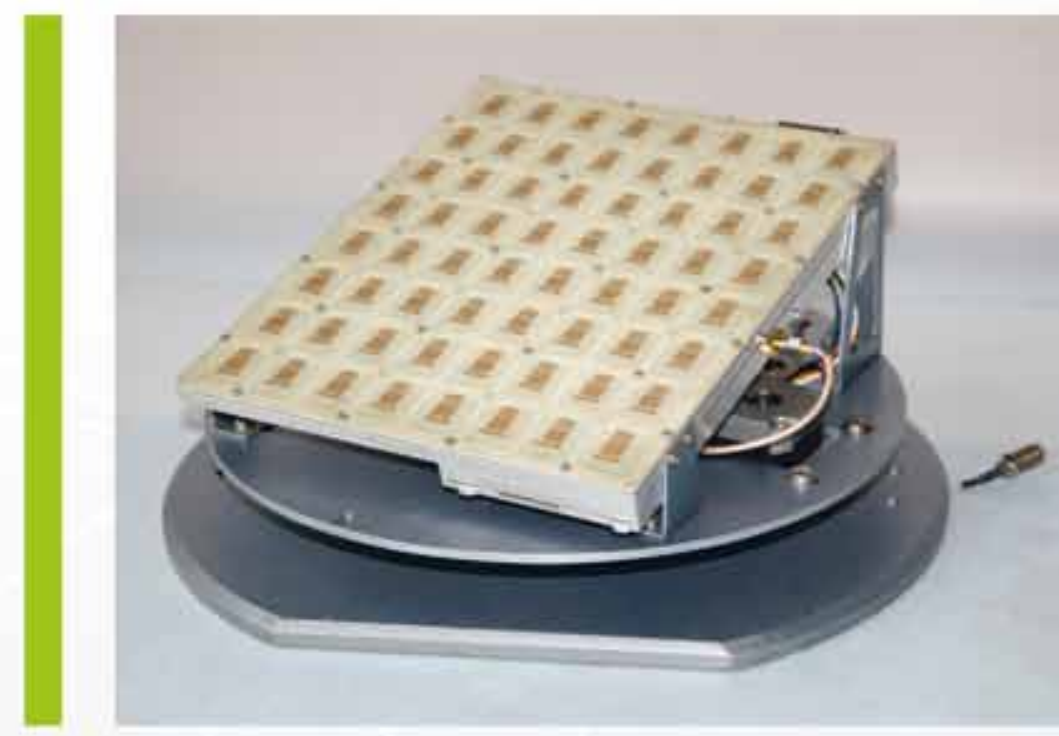

Проведение измерений электрических характеристик радиотехнических изделий

Разработка программы и методики испытаний радиотехнических изделий Заказчика

Разработка программного обеспечения для автоматизации измерений

Разработка измерительных стендов для испытаний радиотехнических изделий

В качестве исполнителей привлекаются профильные специалисты с многолетним опытом работы в областях научных исследований и опытноконструкторских работ. Подробнее о полном перечне услуг и технических подробностях можно узнать, связавшись с нами. 